8 Stilwell JA, Young D, Cunnington DA. Evaluation of laboratory tests in hospitals. Ann Clin Biochem 1980;17:281-6.

9 Sandler G. Do emergency tests help in the management of acute medical admissions? Br Med $\mathrm{F}$ 1984;289:973-7.

10 Cohen DI, Jones P. Littenberg B, Neuhauser D. Does cost information availability reduce physician test usage? Med Care 1982;20:286-92.

1 Grivell AR, Forgie HJ, Fraser CG, Berry MN. Effect of feedback to clinical staff of information on clinical biochemistry requesting patterns. Clin Chem 1981:27:1717-20.

12 Rhyne RL, Gehlbach SH. Effects of an educational feedback strategy on physician utilisation of thyroid function panels. I Fam Pract 1979;8:1003-7.

3 Martin AR, Wolf MA, Thibodeau LA, Dzau V, Braunwald E. A trial of two strategies to modify the test-ordering behavior of medical residents. N Eingl f Med 1980;303:1330-6.

14 Wickings I. Putting it together. The patient, the purse, and the practice. Lancet 1977;i:239-40.

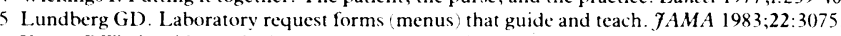

16 Young DW. An aid to reducing unnecessary investigations. Br Med f 1980;281:1610-1.

7 Mintz PD, Lauenstein K, Hume J, Henry JB. Expected hemotherapy in elective surgery. A follow up. 7AMA 1978;239:623-5

18 Hardwick DF, Morrison JI, Tvdeman J, Cassidy PA, Chase WH. Structuring complexity of testing: a process orientated approach to limiting unnecessary laboratory use. Am f Med Technol 1982:48:605-8.

19 Dixon RH, Laszlo J. Utilisation of clinical chemistry services by medical house staff. Arch Intem Med 1974;134:1064-7.

\section{Electromagnetic induction of bone?}

Pulsed electromagnetic treatment of ununited fractures has been employed in over 11000 patients world wide (A A J Goldberg et al, Bioelectrical Repair and Growth Society, second annual meeting, 1982), but the clinical value of this technique remains open to question. It has a long history. In 1853 a report appeared in the United States Medical Times and Gazette describing the successful use of electrical treatment for an ununited fracture, but this was largely ignored in conventional medical circles and dismissed as yet another example of nineteenth century quackery. ${ }^{1}$ Over 100 years later reports began to appear suggesting that the effects of electrical activity on bone formation required further study. ${ }^{2}$

The body and its individual cells are constantly subjected to electromagnetic forces-partly endogenous, from, for instance, the myocardium; and partly external forces, such as the earth's magnetic field and high tension cables. Bone itself develops electrical charge under varying load conditions. Attempting to bend a long bone causes a build up of positive charge on the convex or tensile surface and a transient negative charge on the compressed or concave surface. ${ }^{3}$ Wolff's law states that bone subjected to compression becomes stronger, and it has been widely suggested that electrical phenomena underlie the physiology of adaptive remodelling, though the direct evidence for this is scant. ${ }^{4}$

The formation of new bone has been found with the use of tetracycline labelling, close to areas where a steady electrical negative charge is maintained ${ }^{\mathrm{s}}$; and studies of rabbit fibulas showed formation of bone near the negative electrode when a current of between 5 and $20 \mu \mathrm{A}$ was passed across a fracture. ${ }^{6}$ When this current was increased to $100 \mu \mathrm{A}$ necrosis of the tissue was observed, particularly close to the positive electrode. ${ }^{7}$ One criticism of research using implanted electrodes is that an invasive procedure might itself stimulate new bone formation. It has also been argued that "ions" may leak from the electrodes and polarisation occur, producing electrolytic biproducts. ${ }^{8}$ Electromagnetic induction using two external electrodes, electrically insulated from the patient, was employed to overcome these criticisms; with chick tibia as the model, chondrogenesis was found to be inhibited and calcification stimulated. ${ }^{9}$

Numerous explanations were produced for the observed effects in rabbit fibula, chick tibia, and the metatarsal of the weanling mouse. Depletion of oxygen near the negative electrode, increased $\mathrm{pH}$ due to the production of hydroxyl radicals, or increased cyclic adenosine monophosphate concentrations in intact tissues were reported, ${ }^{10}$ though this last has been disputed. "At times these hypotheses were accepted as proved theories, and on the basis of 14 uncontrolled clinical trials on 595 patients with a wide variety of conditions claims were made that electromagnetic treatment resulted in " $50 \%$ faster healing," "increased bone growth," "more stability at two weeks," and " $30 \%$ less time to stability." 12 Success rates claimed for electrical treatment of ununited fractures ranged from $72 \cdot 5 \%{ }^{13}$ and $92 \cdot 5 \%^{14}$ using direct current with implanted electrodes to $80 \%$ using pulsed electromagnetic fields. ${ }^{15}$ A success rate of $93 \%$ was reported when this treatment was combined with bone grafting. ${ }^{16}$ When failure did occur it was thought to result from "inadequate electricity, synovial pseudoarthrosis or infection, or dislodgement of the electrodes." Each series emphasised the importance of "proper cast immobilisation using a nonweight bearing plaster," ${ }^{10}$ but only one author went so far as to state that, "mechanical fixation and bone grafting proved more critical for successful union than did the electrical stimulation," and he continued, "electrical stimulation does not compensate for inadequate fracture fixation." 17

These clinical studies have highlighted three topics of uncertainty. The first is the definition of "non-union" of a fracture. That "non-union exists when the surgeon considers that the fractures will not heal without surgical intervention" is clearly open to question, ${ }^{18}$ but so also is the definition of "no progressive healing over a three month period" 13 when oblique radiographs have not been taken..$^{14} \mathrm{~A}$ tenth of the fractures which Connolly considered initially to be ununited healed spontaneously without further treatment. ${ }^{17} \mathrm{He}$ argued that pain, mobility of the fracture on fluoroscopy, intraosseous phlebography, ${ }^{1920}$ and bone scintigraphy ${ }^{21}$ were important in deciding which patients to include in the study. The mere radiological persistence of a fracture line does not invariably indicate non-union.

The second difficulty has arisen through the use of historical controls. By definition, an ununited fracture should remain ununited, unless modified by, for instance, the introduction of bone graft. Grafting procedures are reported to produce a union rate of between $85 \%$ and $98 \%$ at the first attempt, dependent on the severity and site of the nonunion ${ }^{22}$ and the grafting technique..$^{23}$ This figure falls to $66 \%$ with the second grafting and $64 \%$ at the third attempt. ${ }^{24}$ But without grafting $12.5 \%$ of fractures of the tibial shaft of 12 months' duration still unite with conservative management alone..$^{25}$ In a series of 804 fractures of the shaft of the femur and tibia treated with prolonged immobilisation WatsonJones reported no case of non-union. ${ }^{26}$ Many of these fractures were multiple, comminuted, contaminated, or heavily infected.

Thirdly, the criterion for "success" is the development of a "sound bony union." This end point is by no means always clear, particularly in patients who have had previous surgery with grafting and considerable scarring and distortion of the bone. For "success" to be achieved with electrical treatment several strict conditions must be met. A "cooperative patient" is required to change the anode pad every other day when direct current is used to avoid skin irritation. A plaster of Paris cast is applied "to protect the electrodes," and "non-weight bearing is essential." If weight bearing occurred, "the true effect of the applied constant direct current is not realised ... and irritation may develop around the cathodes or the cathodes may break. ${ }^{14}$ Of necessity the patient's activity is reduced by having to plug in the machine or carry around an electricity supply. Frequent visits to the 
clinic are required to check the equipment. Could these strict conditions possibly influence bony union? Introductory statements to review articles such as "At this time the weight of evidence gathered from both laboratory, animal, and clinical studies indicates that electrical forces can stimulate bone growth. The prime question thus becomes, how does it work?" ${ }_{27}$ and "A double blind trial is impracticable" ${ }_{28}$ suggested that this question is not always addressed.

Fortunately, such statements did not deter Barker et al from randomly allocating 16 patients with ununited tibial fractures of at least 12 months' duration to treatment with either an active or dummy pulsed magnetic field stimulator contained within a full non-weight-bearing plaster..$^{29}$ The two groups were reviewed after 24 weeks. The fractures in five of the nine patients with an active stimulator united compared with five of the seven of those in the control group. Finding no difference between the two groups, the authors argued the efficacy of conservative treatment. This preliminary communication was the first reported double blind trial of pulsed magnetic field therapy for tibial non-union in man. We and 11000 patients world wide await the results of further double blind controlled trials.

Clinical Reader in Orthopaedic Surgery,

JOHN NIXON

Nuffield Orthopaedic Centre,

Oxford OX $37 \mathrm{LD}$

1 Stillings D. Healing fractures electrically. Fourmal of the Association for Advancement of Medicul Instrumentation 1974;8:259.

2 Bassett CAL, Pawluk RJ, Becker RO). Effects of electrical current on bone formation in vivo. Nature 1964;204:652-4.

3 Gross D, Williams WS. Streaming potential and the electromechanical response of physiologically moist bone. f Biomech 1982;15(4):277-95.

4 Borgens R. Fndogenous ionic currents transverse intact and damaged bone. Science 1984;225: 478-82.

5 Rubinacci A, Tessari L. A correlation analysis between bone formation rate and bioelectric potentials in rabbit tibia. Calct Tissue Int 1983;35:728-31.

6 Friedenburg ZB, Roberts PG, Didizian NH, Brighton CT. Stimulation of healing by "direct current" in the rabbit fibula. 7 Bone 7 oint Surg 1971;53A: 1400-8.

Hassler CR, Rybicki EF, Diegle RB, Clark LC. Studies of enhanced bone healing via electrica stimuli. Clin Orthop 1977;124:9-19.

8 Bassett CAL. Pulsing electromagnetic fields: a new method to modify cell behaviour in calcified and noncalcified tissues. Calcif Tissue Int 1982;34:1-8.

9 Fitton-Jackson S, Jones DB, Murray JC, Farndale RW. The response of connective and skeleta tissues to pulsed magnetic fields. In: Transactions of the first annual meeting, Bioelectrical Repair and Growth Society. Philadelphia: Bioelectrical Repair and Growth Society 1981:1-85.

10 Norton LA, Rodan GA, Bourrett LA. Epiphyseal cartilage CAMP changes produced by electrical and mechanical perturbations. Clin Orthop 1977;124:59-68

11 Fitton-Jackson S, Bassett CAL. The response of skeletal tissues to pulsed magnetic fields. In Richards RJ. Rajan KT, eds. Tissue culture in medical research (II). Oxford: Pergamon Press, 1980:21-8

12 Spadaro J. Electrically stimulated bone growth in animals and man. Clin Orthop 1977;122:325-32

13 Brighton CT, Black J, Friedenberg ZB, Estherhi JL, Day LJ, Connolly JF. A multicenter study of the treatment of non-union with constant direct current. F Bone foint Surg 1981;63A:2-13.

14 Heppenstall RB. Constant direct current treatment for established non-union of the tibia. Clin Orthop 1983;178:179-84

15 Bassett CAL, Mitchell SN, Gaston SR. Pulsing electromagnetic field treatments in ununited fractures and failed arthrodeses. $\mathcal{F}$ AMA 1 1982;247:623-8

16 Bassett CAI., Mitchell SN, Schink MM. Treatment of therapeutically resistant non-unions with bone grafts and pulsing electromagnetic fields. F Bone fout Surg 1982;64A:1214-20.

17 Connolly JF. Selection evaluation and indications for electrical stimulation of ununited fractures Clin Orthop 1981:161:39-53.

18 Watson $\mathrm{J}$. The electrical stimulation of bone healing in cases of non-union and delayed union. In McKibbin B, ed. Edinburgh: (Churchill Livingstone, 1983:131-53

19 Puranen J, Kaski P. The clinical significance of osteomedullography in fracture of the tibial shaft. f Bone Foint Surg 1974:56A:759.

20 Rhinelander F. Circulation of bone. In: Bourne $\mathrm{G}$, ed. The hochemistry and phystology of hone. Vol 11. New York: Academic Press, 1972:2-77.

21 Esterhai JL, Brighton CT, Heppenstall RB, Alavi A, Desai AG. Detection of synovial pseudarthroses by $99 \mathrm{~m}$ Ti scintigraphy. Clin Orthop 1981;161:15-23.

22 Muller ME, Thomas RJ. Treatment of non-union in fractures of long bones. Clin Orthop 1979:138:141-53.

23 Reckling WR, Waters $\mathrm{CH}$. Treatment of non-union of fractures of the tibial diaphysis by

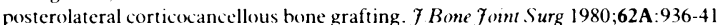

24 Boyd HB, Lipinski SW, Wiley JH. Observations on non-union of the shafts of long hones with statistical analysis of 842 patients. F Bone foint Surg 1961;43A:159-68.

25 Nicoll EA. Fractures of the tibial shaft-a survey of 705 cases. 7 Bone foint Surg 1964;46B: $373-87$

26 Watson-Jones $R$. Slow union of fractures with a studv of 804 fractures of the shafts of tibia and femur. Br 7 Surg 1943:30:260-76.

27 Becker RO. Electrical osteogenesis-- pro and con. Calcif Tissue Res 1978;26:93-7.

28 De Haas WG, Watson J, Morrison DM. Non-invasive treatment of ununited fractures of the tibia using electrical stimulation. F Bone foimt Surg 1980;62B:465-70.

29 Barker AT, Dixon RA, Sharrard WJW, Sutcliffe ML. Pulsed magnetic field therapy for tibia non-union: interim results of a double blind trial. Lancet 1984;i:994-6

\section{Antibiotics in hand infections}

Antibiotics have brought respite for many patients suffering with severe infections, but their indiscriminate use may be damaging. Nowhere is this more true than in the hand. The old aphorism that there is "no such thing as a minor hand infection" remains true. Furthermore, hand infections which might be thought to be minor by both patient and doctor may be transformed into major problems if antibiotics are prescribed unwisely. While dogma may be dangerous, as a general rule the outpatient prescription of antibiotics alone has no place in treating hand infections. Where antibiotics are indicated-and they often are-is as an adjuvant to surgical treatment; or when surgical treatment is not indicated antibiotics may be required parenterally, together with splintage and elevation of the arm in hospital. ${ }^{1-10}$

The common hand infections are paronychia (whitlow), pulp space infection (felon), boils, and cellulitis; together they account for $90 \%$ of the total. Acute paronychia occurs in three stages of severity. Firstly, there may be pus between the reflected cuticle and the nail; secondly, a small amount of pus may have formed under the lateral part of the nail; and, thirdly, the so called "horseshoe" paronychia may have developed, with pus insinuated between the proximal nail and the nail germinal matrix. All three forms are best treated surgically, followed by daily dressings and splintage. Antibiotics are seldom necessary. Pulp space infections require incision and drainage, daily dressings, and splintage of the digit, and again antibiotics are seldom necessary. Only when the infection is seen late and a "collar stud" type of abscess has developed, possibly with secondary spread to the bone, are adjuvant antibiotics appropriate. Boils on the hand and wrist occur almost exclusively on the dorsal aspect, in hair bearing skin, and require incision and drainage followed by splintage. If there is surrounding erythema or pronounced swelling the hand should be elevated and antistaphylococcal antibiotics given parenterally.

Cellulitis is almost always the result of infection with $\beta$ haemolytic streptococci, and treatment should consist of splintage of the hand in the safe position, elevation, and intravenous benzylpenicillin.

The less common but more serious infections are the abscesses that may form in the web space, the palmar space, or the thenar space. All these require incision and drainage under regional or general anaesthesia and a tourniquet. Antistaphylococcal antibiotics, given parenterally, should be given initially until organisms have been cultured and their sensitivities are obtained. Infection of the flexor tendon sheath requires incision, drainage, and irrigation of the tendon sheath, together with parenteral benzylpenicillin. Septic arthritis may occur after an injury initially thought to be trivial; it may also result from a punch in which the clenched fist strikes the incisor teeth. The required treatment is opening and irrigation of the joint and the administration of broad spectrum antibiotics to cover the wide range of organisms present in the mouth.

Pyogenic granulomas require curettage. Orf is a self limiting granulomatous condition, the result of inoculation of the skin with a virus that lives in the incisor teeth of sheep. Herpes simplex and, more recently, genital herpes may produce unusual patterns of infection around the nail. Tuberculosis may affect bones or joints, but in Britain the flexor tendon synovium is the commonest site of infection in the hand, producing the so called "compound palmar 